\title{
Trabalho associado, autogestão e arquitetura popular: uma experiência exitosa
}

\author{
MARIA ROSA LOMBARD \\ Doutora em Relações de Gênero, Trabalho e Profissões (Université Paris X-Nanterre) \\ Pesquisadora na Fundação Carlos Chagas, São Paulo. \\ mlombardi@fce.org.br
}

\begin{abstract}
Resumo $\mathrm{O}$ artigo analisa os principais resultados de pesquisa sobre uma organização de trabalho associado entre arquitetos(as), sediada na cidade de São Paulo. Dedicam-se à assessoria técnica para habitação popular e estão ativos desde 1990. Atualmente, congrega 12 associados, 11 arquitetos(as) e um cientista social. Trata-se de um coletivo jovem, pois seus associados têm entre 25 e 36 anos. A pesquisa objetivou recuperar a 'história de vida' do empreendimento, identificar e analisar eventuais mudanças na organização do trabalho, nos seus objetivos e nas atividades. Procurou conhecer, também, a divisão sexual do trabalho técnico e a avaliação dos(as) associados(as) sobre essa experiência alternativa de trabalho e as expectativas para o futuro. Metodologicamente, a pesquisa se define como estudo de caso e, para a coleta de dados, utilizou a análise documental, as entrevistas pessoais (18, com associados e ex-associados) e a observação participante durante reuniões de trabalho do coletivo.
\end{abstract}

Palavras-chave: trabalho associado; autogestão; sociologia do trabalho; relações de gênero; arquitetura

$\mathrm{O}$ TEXTO TRAZ RESULTADOS DE ESTUDO sobre uma organização de trabalho associado entre arquitetos(as) sediada na cidade de São Paulo, a USINA - Centro de Trabalhos para o Ambiente Habitado ${ }^{1}$. O empreendimento está ativo desde 1990 e, atualmente, congrega 12 associados, 11 arquitetos(as) e um cientista social. Trata-se de um coletivo muito jovem, pois seus associados têm entre 25 e 36 anos. $\mathrm{O}$ artigo está organizado em três partes: a primeira traz as características principais do empreendimento e da gestão e analisa as mudanças no tempo; a segunda enfoca o trabalho realizado e as contradições específicas de que ele se reveste num empreendimento autogestionário; a terceira discute as possibilidades e os limites da democracia participativa e da autogestão no coletivo. Finalmente, a quarta parte analisa a divisão sexual do trabalho, desvelando padrões de gênero particulares ao co-

1 Este artigo foi extraído da pesquisa finalizada em 2010 intitulada USINA: uma Experiência de Trabalho Associado entre Arquitetos e Arquitetas Militantes, que objetivou conhecer como se organizou e desenvolveu essa experiência de trabalho associado, recuperando a 'história de vida' do empreendimento, identificando e analisando eventuais mudanças na organização do trabalho, nos objetivos e nas atividades, privilegiando a ótica das relações de gênero. Essa pesquisa foi desenvolvida no Departamento de Pesquisas Educacionais da Fundação Carlos Chagas com financiamento do CNPq, esteve associada ao projeto A Crise do Trabalho e as Experiências de Geração de Emprego e Renda: as Distintas Faces do Trabalho Associado e a Questão de Gênero, realizada pela Faculdade de Educação e pelo Instituto de Filosofia e Ciências Humanas (IFCH) da Universidade Estadual de Campinas (UNICAMP), com o apoio financeiro da Fundação de Amparo à Pesquisa do Estado de São Paulo (FAPESP). Cumpriu ainda a função de pesquisa de pós-doutorado junto ao IFCH/UNICAMP. 
letivo, bem como aqueles que são comuns em ambientes profissionais majoritariamente masculinos.

\section{O empreendimento (1990-2010): características de gestão e ideologia}

A USINA nasceu na cidade de São Paulo, em 1990, e seus associados e suas associadas tiveram e têm a marca da militância profissional e política. Eles e elas creem que é possível construir uma sociedade em que prevaleçam relações mais democráticas, participativas e igualitárias entre todos e disponibilizam seus saberes técnicos e de gestão nessa direção, assessorando a construção de moradias para as camadas mais pobres da população. Seguindo a definição de Dal Ri (2004), a USINA pode ser definida como uma OTA, isto é, uma organização de trabalho associado, que se formou com base em uma ideologia de transformação social, a qual, simbolicamente, fortalece o coletivo e contribui para sua sobrevivência. A USINA caminhou para a adoção da autogestão interna no decorrer de sua vida, pois, embora a formação inicial estivesse próxima do modo de funcionamento de um escritório de arquitetura, já o era em moldes não convencionais.

A USINA é um agrupamento de arquitetos, engenheiros e cientistas sociais que prestam serviços de assessoria técnica para movimentos de moradia em obras que se utilizam de mutirões em sistema de autogestão. Atualmente, existem algumas linhas de financiamento público destinadas a entidades ou movimentos sociais e voltadas para a construção de moradias em sistema de mutirão autogerido. Nesse sistema, normalmente, há participação dos 'mutirantes' - uma parcela dos futuros moradores que se propõe a contribuir com seu trabalho para a obra coletiva, de forma não remunerada - restrita aos finais de semana, desenvolvendo tarefas mais simples. Durante a semana, o trabalho é realizado pelas empreiteiras convencionais, contratadas pelo movimento de moradia. Nesse sentido, o mutirão difere da autoconstrução que, como informou um entrevistado, é uma empreitada individual, destinada ao uso próprio, que emprega recursos de uma família para a construção da casa e/ou para compra do terreno. A USINA, como as demais assessorias técnicas, é remunerada em, no máximo, $4 \%$ do valor do financiamento obtido, em parcelas mensais. Costumeiramente, em mutirões, o órgão financiador estipula 13 liberações de verbas, uma por mês, atreladas ao cumprimento de etapas pré-estabelecidas da obra. $\mathrm{O}$ atraso no cumprimento dessas etapas da construção é comum, o que compromete a liberação regular de verbas e, na sequência, o pagamento regular do trabalho das assessorias.

Desde os primórdios, a USINA foi um empreendimento econômico em que os associados visam obter sua própria sobrevivência através do trabalho profissional. Trabalham com ideais autogestionários que procuram im- plementar nos mutirões e na própria organização interna, mas eles mantêm no horizonte a perspectiva do negócio coletivo, do qual sempre esperaram obter remuneração adequada para seu trabalho profissional. Na USINA, a identidade central é a profissional. A identidade coletiva de arquitetos(as) prevalece e traz coesão ao grupo e é seu norte. É recorrentemente invocada quando circunstâncias objetivas externas lhes colocam desafios ou propõem situações potencialmente desafiadoras à afirmação daquela identidade. Por exemplo, a autoridade técnica é recolocada em pauta em casos em que o movimento ou a associação de moradores decide alterar um elemento da obra ou do projeto à revelia das orientações da assessoria já aprovadas em assembleias. Também, os limites da atuação profissional são invocados quando lhes demandam assessoramento em assuntos que extrapolam suas expertises técnicas; ainda, a reafirmação do valor do trabalho profissional de arquitetura é enfatizada quando a coordenação insiste junto aos associados para que sejam cobrados repasses de verbas, em tempo hábil, dos clientes (movimentos e associações de moradores). Foi frequente ouvi-los dizer nas reuniões gerais, "nós não somos Estado", "nós não somos movimento social", "nós não somos associação de moradores", "nós somos arquitetos".

Em seus vinte anos de vida, a USINA estabeleceu relações com sujeitos sociais, políticos e profissionais diferenciados e esteve sujeita a variações no volume e no tipo dos serviços prestados, em função de oscilações econômicas e de mudanças nas políticas públicas de habitação popular nos âmbitos municipal, estadual e federal. Não poderia ser diferente, pois, como uma unidade econômica produtora de serviços técnicos, a USINA encerra a contradição apontada por Dal Ri (2004) de ser uma alternativa ao capitalismo e, ao mesmo tempo, prestar serviços que competem no mercado com empresas capitalistas.

Manter-se no mercado sem comprometer os valores ideológicos é o dilema ou paradoxo histórico das organizações de trabalho associado inseridas no sistema capitalista, particularmente para as com raiz ideológica preponderante. Esse dilema tem sido permanentemente colocado à USINA, que o enfrenta colocando em prática algumas estratégias gerenciais, tanto na gestão da primeira geração (1990-2004), como na da segunda (2004-2010). Na gestão da primeira geração, o trio de arquitetos fundadores procurava diversificar as possibilidades de trabalho profissional para além dos movimentos sociais, realizando consultorias para órgãos públicos considerados progressistas ou trabalhando como docentes. Essa perspectiva lhes permitiu sobreviver em momentos de crise, ocasionadas por oscilações econômicas e, sobretudo, pelas mudanças de orientação nas políticas públicas municipais de habitação. Na gestão da segunda geração, as atividades foram mais focadas no trabalho com movimentos de moradia. Estreitado o campo de ação, a atual gestão delimitou o teto máximo de vinte horas semanais de dedicação ao empreendimento, praticamente obrigando que todos tenham outras atividades profissionais concomitantes que lhes ga- 
rantam a subsistência, ou consigam a cobertura de bolsas de estudo de mestrado e/ou doutorado. Todos os entrevistados repetiram que gostariam de trabalhar só na USINA se pudessem ser regularmente remunerados, o que, atualmente, eles mesmos consideram uma utopia.

Contar com auxiliares ou estagiários foi outro aspecto que variou entre as duas gestões e essa questão ultrapassa o âmbito administrativo, porque tem influência direta nas possibilidades de expansão do negócio. Nos primeiros anos da primeira gestão, quando Luíza Erundina era prefeita de São Paulo, a USINA 'tocava' diversos mutirões simultaneamente. Os fundadores contratavam estudantes estagiários - denominados colaboradores nos estatutos - para acompanhá-los e dividir com eles o trabalho nas várias obras, que supervisionavam pessoalmente. Somente assim puderam trabalhar 'com escala'. Na atual gestão, foi abolida a figura do estudante/estagiário/ colaborador, inclusive dos estatutos, aparentemente por duas razões, quais sejam: apenas um graduado pode ser responsável por uma obra segundo determinações do órgão de classe (Conselho Regional de Engenharia, Agronomia e Arquitetura - CREA); e, dentro da perspectiva de democracia e autogestão internas implantadas atualmente, não mantêm funções que consideram subalternas, como a de estagiário. Todos os 12 associados são ao menos graduados. Entre eles, há um cientista social, todos os outros são arquitetos. Com uma equipe assim reduzida, em tese trabalhando em período parcial, sem auxiliares, as possibilidades de expansão do negócio ficam limitadas. De fato, uma das grandes preocupações do atual coletivo é 'andar no limite das próprias pernas'.

A contradição de representar uma alternativa ao sistema capitalista e nele estar inserida, foi particularmente aguçada em dois episódios: a pesquisa FI$\mathrm{NEP}^{2}$ na primeira geração e o projeto Companhia de Desenvolvimento Habitacional Urbano do Estado de São Paulo (CDHU), na segunda. Ambos confrontaram a USINA com outras lógicas de trabalho, de organização do trabalho e de gestão e expuseram cruamente as limitações da atuação profissional do coletivo. No caso da pesquisa FINEP, uma equipe especial foi contratada, ficou sediada no escritório da USINA; tinha divisão do trabalho, hierarquia, remuneração e expectativas diversas dos associados. Transformou-se num 'corpo estranho' dentro da USINA e causou inúmeros problemas, tanto entre associados e contratados da pesquisa, como entre os próprios associados. A pesquisa FINEP acabou sendo considerada um elemento altamente desestabilizador, que contribuiu para "implodir a relação entre várias pessoas”, ajudando a desmantelar a equipe, já pressionada por uma conjuntura de crise. O projeto CDHU ainda está no âmbito das intenções e possibilidades de trabalho da atual gestão, não se concretizou e, talvez, não se concretize. Exigirá a contratação de uma equipe especial para executá-lo, uma coordenação, divisão de trabalho e outros elementos que estiveram presentes no caso da pesquisa FINEP. Os atuais coordenadores relutam em aceitá-lo, pois acreditam que os mesmos elementos desestabilizadores da experiência anterior estarão presentes e serão portadores dos mesmos riscos para a sobrevivência do coletivo.

Entre alterar o modus operandi, a filosofia de trabalho e os princípios ideológicos e obter os tão necessários recursos financeiros por meio de projetos que funcionam com outra lógica, a de mercado, a USINA tem escolhido a primeira opção. O coletivo se mostra consciente das limitações que essa opção lhes impõe, as aceita e as valoriza. Compreendem que a sobrevivência da experiência USINA implica militância política e profissional, aliada a uma forte vertente de educação continuada, concretizada nas reuniões de trabalho. Cornforth (apud Lima, 2008) é um dos autores que assinalam que os associados têm papel ativo no destino dos empreendimentos, fazem escolhas sobre a estrutura, a gerência, o grau de democracia interna. Não nega, porém, que fatores como crescimento do negócio, criação de papéis especializados e pressão por eficiência podem questionar os graus de democracia implementados. Frente a esses desafios, nova rodada de posicionamentos, normalmente, se põe em marcha, como nas situações que acabamos de descrever.

Em conformidade com Dal Ri (2004), as formas de recrutamento das organizações de trabalho associado seguem uma lógica diferente da do mercado. Costumam ser endógenas, por indicações dos associados. Vimos esse mecanismo em funcionamento na USINA que, durante sua vida, tem recrutado colegas de faculdade (Faculdade de Arquitetura e Urbanismo da Universidade de São Paulo - FAU/USP, sobretudo), alunos e ex-alunos dos arquitetos fundadores, arquitetos vinculados a partidos políticos de esquerda, a movimentos de moradia e, também, que trabalharam ou trabalham em outras assessorias técnicas. Mas o que importa realmente é que os candidatos tenham a mesma perspectiva sobre o trabalho técnico e político executado na USINA. Essa estra-

2 Financiadora de Estudos e Projetos, vinculada ao Ministério da Ciência e Tecnologia. A pesquisa em questão voltou-se para a reflexão sobre experiências de construção popular na modalidade mutirão e envolveu um grupo de pesquisadores vinculados a diversas instituições acadêmicas e assessorias técnicas, a USINA entre elas. Denominou-se Políticas Habitacionais de Moradia por Mutirão e Processos Autogestionários: Balanço Crítico de Experiências em São Paulo, Belo Horizonte e Fortaleza, e foi realizada entre 1998 e 2001. 
tégia estimula a cooperação entre os arquitetos e tem fomentando a construção de uma comunidade mais coesa, fortalecida frente à persistência das contradições nas relações de trabalho.

Diferentemente do que aponta a autora citada quando se refere às OTAs que pesquisou, porém, sempre houve uma alta rotatividade de pessoal na USINA. Um dos principais motivos dessa peculiaridade reside na questão da remuneração, baixa para os padrões do mercado e irregular. O envolvimento pessoal, político e profissional intenso requerido para nela trabalhar é outro motivo importante da rotatividade. O esgotamento físico em razão do excesso de trabalho nas obras e no escritório, o desgaste psicológico derivado do próprio trabalho e a existência de obrigações familiares e de filhos têm pesado na decisão de deixar o coletivo, tanto por parte dos homens, como das mulheres. Aqueles e aquelas que têm obrigações familiares, os que não encontram outra fonte de renda compatível e os mais velhos tendem a se desligar da USINA. Só nela permanecem se tiverem ligações muito fortes com sua proposta, como é o caso de dois dos arquitetos fundadores, hoje na faixa dos cinquenta anos. Contudo, mesmo permanecendo associados e desempenhando o papel de referências técnicas para a atual geração, eles se mantêm afastados do cotidiano da USINA.

\section{O trabalho: satisfação pessoal e profissional versus precariedade}

O trabalho técnico altamente satisfatório foi um dos motivos principais indicados por todos os entrevistados para se integrarem à USINA e nela permanecerem. Destacaram a possibilidade de participar de todas as etapas do trabalho arquitetônico, desde a fase de criação e concepção - o projeto - até a execução, nos canteiros de obra. Nas palavras de um associado, a USINA lhes propicia desenvolver "um fazer profissional que desenvolve as várias faculdades humanas" porque o trabalho não é alienado. Isto é, não é fragmentado, repetitivo, sem sentido porque desligado da concepção, sem possibilidade de intervenção ou de participação técnica, como acontece nos escritórios convencionais, em que grande parte dos jovens arquitetos é absorvida. As etapas do trabalho técnico e suas implicações políticas e sociais são discutidas e decididas nas reuniões semanais de trabalho e formação, o mais 'horizontal' e 'democraticamente' possível. Ou seja, não há uma hierarquia rígida da qual emanam orientações e decisões que todos devem acatar. Como afirmou uma arquiteta, se a autoridade existe, ela provém, em princípio, da experiência e do poder de argumentação, não de uma posição hierárquica ou da posse dos bens de produção. O controle do trabalho técnico costuma ser levado à risca pelas equipes da USINA, embora não se possa descartar certo grau de interferências política, administrativa e relacional nesse quesito.

As relações de trabalho tendem a ser mais democráticas e participativas. Ainda no âmbito das relações de trabalho, é forçoso ressaltar a dimensão de precariedade de que o trabalho na USINA se reveste. Rodgers (apud Leite, 2009) identifica como dimensões da precariedade o grau de instabilidade no trabalho, o grau de controle dos trabalhadores sobre as condições de trabalho e seu ritmo, a proteção dispensada por uma legislação ou por contratos coletivos e os rendimentos. Se seguirmos estritamente essas dimensões, poderemos concluir que o trabalho dos arquitetos se dá na precariedade, pois estão presentes a instabilidade, a dificuldade de controlar as condições, o ritmo de trabalho e os rendimentos e a inexistência de proteção dispensada pela legislação previdenciária e trabalhista ou por contratos coletivos. No entanto, o trabalho desse grupo tem suas especificidades e entendê-las ajudará a melhor qualificá-lo.

Quanto à instabilidade, se ela é inexistente em termos de vínculo de trabalho - pois o arquiteto será associado, em princípio, durante toda a existência do empreendimento -, por outro lado, a instabilidade é intrínseca à opção de trabalhar com mutirões em autogestão, junto com movimentos de moradia. Fica-se ao sabor das mudanças de orientação político-partidária das sucessivas administrações municipais, estaduais e federais, que se refletem nas políticas públicas de habitação popular priorizadas nas diversas gestões. Mesmo na existência de políticas públicas que apresentem programas de financiamento para mutirões autogeridos por movimentos sociais, depende-se do ritmo de liberação das verbas e dos trâmites administrativos das máquinas burocráticas. Além disso, a instabilidade da atividade profissional e dos rendimentos dos arquitetos depende, também, da dinâmica dos movimentos sociais parceiros e do gerenciamento das obras pelas associações de moradores, uma vez que as verbas são liberadas conforme o progresso da obra.

As condições e o ritmo do trabalho dos arquitetos da USINA são bastante peculiares. Em primeiro lugar, a concepção dos projetos das habitações é uma produção profissional coletiva, seja porque são discutidos com os colegas nas reuniões gerais, seja porque são apresentados nas assembleias das associações comunitárias de construção e nelas são alterados e referendados. Em outras palavras, um projeto é uma peça construída em processo, não sai acabada da prancheta do arquiteto. E essa sistemática interfere nas condições em que o trabalho é executado e no seu ritmo. Outra especificidade: as jornadas de trabalho dos arquitetos da USINA são flexíveis. Incluem, além do trabalho no escritório, a participação em reuniões com as associa- 
ções - geralmente à noite ou em finais de semana -, além da supervisão do trabalho da empreiteira durante um ou dois dias úteis da semana e do trabalho do mutirão, aos sábados e domingos. Considere-se ainda que as condições e o ritmo de trabalho dos arquitetos da USINA estão atrelados ao tipo de serviço contratado (consultoria, projeto, obra) e ao andamento de uma obra. Se a obra está em andamento, é necessário organizar e supervisionar dois canteiros, um, convencional, durante a semana e outro, alternativo em que procuram implementar princípios de autogestão, nos fins de semana. Se a obra está parada, é necessária também uma 'administração', por exemplo, visitas ao canteiro - menos constantes do que quando a obra está em andamento -, reuniões com as associações, eventuais reparos nas partes construídas, contatos com órgãos públicos e de financiamento.

Finalmente, o controle sobre os rendimentos do trabalho técnico que eles executam é bastante relativo, dependendo da existência ou não de programas de habitação por mutirão e da contratação de projetos que neles se insiram, do valor do financiamento e dos ritmos de liberação de verbas e de repasses dos movimentos. Há outro fator que interfere no controle sobre a entrada de dinheiro: parte dos arquitetos tem dificuldades de cobrar dos movimentos o trabalho profissional realizado pelo coletivo. Esse comportamento 'constrangido' com a cobrança retarda ainda mais a entrada de recursos no caixa. Finalmente, os associados que participaram de projetos recebem valores referentes às horas trabalhadas, adicionados de um valor para transporte e alimentação, sem algum tipo de recolhimento para a seguridade social ou para fins de aposentadoria futura.

Dessa forma, pode-se afirmar que, com exceção do controle sobre o trabalho técnico, as condições de exercício do trabalho, o ritmo, os rendimentos e a cobertura de alguns direitos previdenciários e trabalhistas dos arquitetos da USINA divergem do padrão 'não precário' aceito pela literatura. Complementarmente, se há indícios concretos de trabalho precário na USINA, a permanência dos associados nessas condições, por vários anos, acaba engendrando um processo de precarização (Leite, 2009, Thébaud-Mony, Druck, 2007). Isto é, a incorporação da instabilidade e da insegurança quanto à existência de trabalho futuro e de remuneração, no coração mesmo do negócio e na vida de cada um dos associados. Cabe, então, a questão: por que alguns associados se submeteram a essa situação de precarização por longos períodos de tempo? Sem dúvida, a convicção política de que é necessário construir uma nova sociedade, menos desigual e mais democrática foi a base político-ideológica de sustentação. A ela, adicionou-se a crença, ou a utopia, de que essa transformação social poderia começar a acontecer a partir da construção do local de morar, reaprendendo um fazer coletivo e democrático, que se espraiaria para as demais áreas da vida. Do lado do saber profissional, por sua vez, sempre houve o desejo de provar a possibilidade de executar obras de qualidade e com preço menor, experimentar soluções tecnológicas construtivas poupadoras de mão-de-obra e de dinheiro, que atendessem às diferentes necessidades da população de renda mais baixa. Mas o preço individual e coletivo dessas opções foi e é alto. A sobrevivência da USINA como um empreendimento esteve em risco algumas vezes. Individualmente, muito tempo da vida pessoal e familiar dos arquitetos foi dedicado ao empreendimento, muitas vezes desestabilizando os laços familiares. Um intenso envolvimento pessoal com os movimentos de moradia parceiros e o com o trabalho consome grande estoque de energia mental, emocional e física. As expectativas de nível de consumo pessoal e familiar tenderam a ser rebaixadas em função do baixo e instável ganho, em alguns casos.

Do outro lado, a sensação do trabalho útil social e politicamente falando, bem feito, reconhecido entre os pares do segmento de habitação popular, certamente contou positivamente para uma maior permanência dos associados. Outro fator importante: o coletivo de profissionais da USINA representa, inequivocamente, um apoio e uma referência para cada um, individualmente. Há contínua troca de informações sobre aspectos técnicos dos projetos, sobre conduta profissional com os movimentos, com os mutirantes, os mestres de obra, as diversas instâncias dos órgãos de financiamento e da administração pública etc. Suas "reuniões gerais", realizadas mensalmente durante a gestão da primeira geração e, uma vez por semana, atualmente, podem ser definidas como espaços de formação profissional, no sentido amplo do termo, englobando técnica e gestão, política, relacionamento profissional e pessoal. Outra faceta positiva: os arquitetos da USINA têm a chance de ter o controle do trabalho técnico, concebem projetos e gerenciam sua execução, alternam trabalho em escritório e no campo, ou melhor, no canteiro de obras. Não são executores de tarefas sem sentido.

Sem dúvida, a permanência na USINA, em condições de trabalho desfavoráveis e com ganhos baixos e instáveis, parece ter sido compensada pelos aspectos positivos do coletivo e do trabalho profissional realizado. Nesse sentido, aqui avançamos a ideia de que, no caso desse coletivo profissional, o balanço entre aspectos positivos e negativos tem ensejado uma aceitação da precariedade no trabalho, por um tempo determinado. É verdade, também, que o ciclo de vida parece ter influência no tempo de permanência dos arquitetos como associados, isto é, parece ser mais fácil estar disponível para o trabalho que lá se faz quando se é jovem, solteiro e sem filhos. Ou quando se é um homem, casado, com filhos, que conta com o suporte doméstico da esposa ou da família. A utopia parece ter que ceder terreno à realidade da vida, que exige 
ganhos regulares para sustentar uma família, mas também pressupõe horários de trabalho menos extensos, finais de semana livres, um ritmo de trabalho menos estafante. Em outras palavras, a precariedade no trabalho vivenciada pelos arquitetos da USINA poderia ser denominada 'precariedade consentida'. Permitida, aceita e valorizada, repleta de sentido social e político, durante certo tempo da vida, que variou, de alguns meses, até mais de uma década, no caso de um dos fundadores. Para todos os entrevistados, associados e ex-associados da USINA, aquela precariedade foi vivenciada por mais de um ano e poderia se falar em um 'processo de precarização consentida', portanto.

Entendemos que as condições de trabalho na USINA estão atreladas à atividade profissional politicamente militante que os(as) associados(as) escolheram desenvolver. Enquanto não se alterarem os cenários político, social e de financiamento da habitação popular, particularmente no segmento mutirão, as condições de exercício do trabalho técnico anteriormente descritas tendem a permanecer. Essa é, a nosso ver, a peculiaridade da USINA que merece ser ressaltada. Nesse sentido, como eles mesmos fazem questão de colocar, a USINA não pode ser classificada como "um fruto dos processos contemporâneos (ou pós-modernos) de decomposição do mundo do trabalho por meio da precarização, terceirização e informalização", ou como uma iniciativa que possa ser classificada no universo da economia social ou solidária. Entretanto, a nosso ver, é impossível negar a existência da precarização do trabalho e da informalidade nas relações de trabalho como constituintes centrais desse empreendimento.

\section{Autogestão e democracia participativa: possibilidades e limites}

Lima (2007) ressalta que autonomia e democratização no trabalho caracterizam a autogestão e, seguindo essa perspectiva, a autogestão sempre esteve presente na USINA. No início do empreendimento, os três fundadores procuravam aplicá-la nas obras, nos mutirões e junto às associações de moradores e aos movimentos parceiros. Essa tentativa prossegue atualmente, em que pesem os diversos fatores intervenientes que lhe colocam limites objetivos. Primeiro, cabe ao movimento de moradia contratante da assessoria decidir qual a profundidade do processo de autogestão que deseja imprimir à obra. Francisco, atual co- ordenador geral ${ }^{3}$, afirmou em seu depoimento que se trata de uma questão econômica: quanto maior for o nível de autogestão, maior a economia de recursos, o que se reverte em maior número de metros quadrados construídos em cada moradia, isto é, em casas ou apartamentos maiores. Segundo, existem limites às três dimensões da autogestão que, de maneira geral, a equipe tenta implementar: o rodízio de tarefas entre equipes do mutirão, a discussão constante das metas e a transparência das contas. O rodízio de tarefas entre equipes de mutirantes é aplicado regularmente, mas encontra limites de qualificação profissional. Existem algumas funções-chave na obra que, quando o movimento não dispõe de pessoas que possam desempenhá-las em tempo integral, devem ser contratadas. A USINA costuma discutir constantemente as metas estabelecidas para a obra com os movimentos e as famílias, mas os limites, neste caso, são dados pelos prazos do cronograma de obras estipulados pelos órgãos financiadores. No que tange à transparência nas contas, princípio central da autogestão, são realizadas assembleias mensais de prestação de contas com as famílias. Neste caso, o grau de transparência e detalhamento das contas que chega às famílias costuma variar conforme o movimento. Segundo uma entrevistada, haveria menos autogestão quando o mutirão é em parceria com o Movimento dos Sem Terra (MST) e o Movimento dos Trabalhadores sem Teto (MTST), pois a prestação de contas é discutida no âmbito da coordenação do movimento e apenas informada às famílias. Pela sua experiência em mutirões em parceria com a União dos Movimentos de Moradia (UMM), ao contrário, a transparência sobre os gastos tenderia a ser maior, uma vez que a discussão da prestação de contas costuma chegar às famílias, além destas poderem sugerir pautas de discussão de seu interesse, à coordenação.

A autogestão interna sempre existiu na USINA, em diferentes graus. Na primeira gestão, sempre houve espaço para discussão, mas as decisões principais do empreendimento - seleção de projetos, escolha de parceiros, controle financeiro e supervisão técnica estavam centralizadas nos fundadores. O processo autogestionário interno se aprofundou na atual gestão, desde 2004, quando os jovens arquitetos assumir am a administração, em sucessão aos fundadores.

A nova geração da USINA introduziu uma série de modificações na organização do trabalho técnico e na administração das finanças. Algumas consolidaram antigas demandas de colaboradores e associados das duas gerações. Primeiro, buscou-se a equalização dos ganhos entre todos, associados e coordenadores, ao estabelecer um único valor/hora que foi recalculado, explicitando custos de transporte, alimentação, 
infraestrutura, chegando-se ao valor de uma 'hora USINA'. Esse é o valor oficial na negociação dos projetos, que, normalmente, não se concretiza. Segundo, a tomada de decisões, fulcro constante de conflitos na primeira geração, passou por um processo de democratização, assumindo-se que tudo seria discutido e acertado coletivamente. Terceiro, a gestão financeira dos projetos passou a ser feita por meio de um fundo único, em que todas as verbas, de todos os projetos, entram. Desse fundo, após pagamentos de manutenção da infraestrutura, saem remunerações devidas a cada um, em função do número de horas trabalhadas declaradas numa planilha individual de controle de horas, auto-preenchível. Quarto, a orientação técnica dos 'mais velhos', os fundadores, é amenizada; a atual geração procura solucionar sozinha todo tipo de problema, embora não prescinda das orientações de Antonio e Cláudio, dois dos fundadores, quando necessárias. Nesse sentido, a influência desses dois fundadores ainda prevalece, em grau menos intenso do que no passado, quando os jovens eram muito mais dependentes das suas diretrizes.

Outro conjunto de modificações foi sendo elaborado pela segunda geração. De início, decidiram se aproximar dos princípios cooperativistas e, nesse sentido, excluíram dos estatutos e do dia a dia algumas funções consideradas subordinadas (estagiários, faxineira, secretária). Em princípio, o coletivo deveria se encarregar delas de forma democrática, fazendo um rodízio dessas funções entre todos. Decidiram também instituir regras de funcionamento mais claras. Por exemplo, acertando um teto máximo de vinte horas semanais de dedicação à USINA, visando eliminar conflitos na equipe em torno do número individual de horas efetivamente trabalhadas, fato comum durante a gestão da primeira geração. $O$ pressuposto atual, dessa forma, é que não exista dedicação exclusiva ao empreendimento e que cada um tenha outras inserções profissionais concomitantes. Outras alterações parecem mirar a maior participação e responsabilização de todos na gestão do empreendimento. A representação pública da USINA perante os movimentos, os órgãos públicos, a academia e outros, por exemplo, antes era feita exclusivamente pelos fundadores e, agora, passou a ser rodiziada entre todos, desde os recém-chegados até os coordenadores, na medida do possível. Apesar dessa constante tentativa de 'dissociá-lo como único representante da USINA', o empreendimento continua sendo identificado com o coordenador geral. As duplas ou os trios de arquitetos que são designados para cada obra assumem a responsabilidade por ela e a gerenciam. No passado, as equipes já se responsabilizavam pela obra, mas não pelo gerenciamento, realizado diretamente pelos fundadores. A função formadora da USINA foi reforçada: as reuniões gerais passaram a ser semanais e são extremamente valorizadas por todos. Nesse am- biente, discutem-se abertamente problemas de gestão, financeiros, técnicos, políticos, colocam-se problemas enfrentados nas obras para a discussão coletiva, resolvem-se conflitos etc. Não resta dúvida de que o grau de democracia autogestionária é alto nesse empreendimento, particularmente a partir de 2004. Servindo-nos de afirmação de Dal Ri e Vieitez (2001, p. 124), a USINA é "uma empresa em que os quadros são os próprios trabalhadores".

Alguns aspectos presentes na gestão da primeira geração se mantiveram iguais, por exemplo a terceirização de serviços especializados, particularmente os de engenharia, pois faltam associados que possam desempenhá-los. No tocante à produção de textos e artigos sobre a USINA, contudo, decidiu-se que, quando individuais, seriam discutidos no coletivo antes da publicação. Até o ano de 2000 não havia esse controle coletivo sobre autoria individual; diversos associados publicaram artigos com autoria individual identificada, até aquela data. Uma modificação de orientação política pôde ser identificada no tocante à clientela preferencial do negócio. $\mathrm{Na}$ primeira geração, a clientela da USINA era os movimentos populares de moradia, mas também se prestavam serviços para prefeituras e órgãos públicos estaduais e federais. Atualmente, a USINA atende preferencialmente movimentos populares por moradia, com prevalência, nos últimos anos, do MTST e também do MST. Só fazem projetos para programas públicos que tenham recursos destinados a moradia de interesse social e que contemplem a gestã o desses recursos pelos movimentos sociais. Houve, aparentemente, uma maior focalização do negócio.

Um ambiente de trabalho associado que procura incorporar princípios da autogestão, porém, apresenta dificuldades e desafios cotidianos, de várias ordens. Talvez a questão mais pungente na USINA seja o grau de envolvimento individual diferenciado com a premissa da democracia e da participação igualitária no negócio. Aquela premissa traz o pressuposto da responsabilidade individual na partilha igual de direitos, mas, também, de deveres. Estes passam pela divisão do trabalho técnico e político, pela igualmente partilhada execução das tarefas rotineiras de apoio administrativo e das incumbências financeiras do empreendimento, por assumir cargas de trabalho segundo as necessidades do coletivo e não segundo os desejos individuais. Mas, como o ideal e o discurso se distanciam da realidade, o peso maior de determinadas tarefas - sobretudo administrativas e financeiras - acaba ficando para alguns, algumas, na verdade. A autogestão não é um processo fácil, uma vez que se trata de reaprender a participar democraticamente e na prática, pois a escola tradicional não prepara para isso. Além do mais, os associados não são mais vendedores de força de trabalho , mas foram moldados pela cultura predominante no mercado de trabalho (a situação de empregado) e não 
conhecem outra forma de se relacionar entre si, com o trabalho e com a empresa. Nesse sentido, a participação no processo democrático de decisões, concretizado nas assembleias das organizações de trabalho associado, é considerada a via por excelência de educação no e para o trabalho associado. Novaes (2009) afirma mesmo que a autogestão é "a magnífica escola”.

Outra diferença entre o ideal autogestionário e a realidade se situa no âmbito do processo decisório que deveria emergir, em tese, integralmente do coletivo. É inegável, contudo, que uma organização de trabalho associado, assim como as demais empresas capitalistas, não pode prescindir de algum grau de liderança. Na USINA, esse papel foi desempenhado particularmente por Antonio e, atualmente, o é por Francisco. Ficou evidente o papel empreendedor desempenhado por esse último arquiteto nas reuniões gerais de trabalho, seja indicando editais de interesse, abertos ou por abrir, para inscrever a USINA, seja localizando, participando de ou propiciando encontros coletivos com pessoas-chave que, potencialmente, poderiam abrir portas para novos trabalhos em espaços acadêmicos, profissionais, dos movimentos, da política. Nas observações realizadas, em geral, dele partiam sugestões para resolução de questões técnicas das obras ou dos projetos, bem como um constante alerta para que todos se posicionassem como profissionais que desempenham um trabalho que tem valor econômico. Enfim, expressava, nas suas observações, uma visão de futuro, e o empreendedorismo de Francisco - nas palavras de Gaiger (2008), um empreendedorismo brando -, é necessário à continuidade do negócio. Ele reconhece seu papel empreendedor, mas preferiria que outros contribuíssem, solidariamente, nessa tarefa constante de prospecção de novos trabalhos.

\section{Arquitetos, arquitetas e divisão sexual do trabalho}

Finalmente, a categoria analítica "relações sociais de sexo" (Kergoat, 2000) orientou a observação e a análise das relações entre os gêneros na USINA. Aquela categoria identifica uma tensão que atravessa todo o campo social, tensão entre o grupo de homens e o grupo de mulheres, que se revela permanente quando se trata do trabalho e da sua divisão. Nesse sentido, as relações sociais de sexo e a divisão sexual do trabalho são indissociáveis. Seguindo essa ótica, a análise desenvolvida centrou-se na identificação da divisão sexual do trabalho técnico entre arquitetos e arquitetas. $\mathrm{O}$ trabalho desenvolvido pelos(as) arquitetos(as) estabelece interfaces com a técnica, a política e a arte, culturas profissionais de forte simbologia masculina. Ao aliar profissão e militância política, o trabalho torna-se extremamente envolvente e exige dedicação quase que exclusiva. Às mulheres, na maioria das vezes, como bem disse Márcia, cabe, além do trabalho técnico, também preparar a 'retaguarda' de apoio do grupo no escritório, ou da dupla de arquitetos na obra. Isso tem significado tomar conta da organização do dia a dia das obras e do escritório, dedicar-se ao financeiro e lidar mais diretamente com as angústias da falta de recursos. Significa também 'atender o cliente', isto é, os movimentos, em suas demandas contínuas, durante a obra. A vertente relacional no exercício da profissão se destaca entre as arquitetas deste empreendimento, da mesma forma que acontecia entre as engenheiras em estudo realizado há cerca de cinco anos atrás (Lombardi, 2005). Da mesma forma aconteceu com o 'trabalho chato', miúdo, picado, invisível de organização, de contatos, de registros, preferencialmente desenvolvido por elas, seja porque a maioria dos homens não o assumia de imediato, seja porque elas se antecipavam em aceitá-lo. Sua voz nas questões decisórias do coletivo, entretanto, precisou ser 'construída' no bloco feminino mais antigo de casa para ser ouvida. Quando consolidada, foi respeitada e permitiu uma dinâmica mais aberta nas reuniões de trabalho. Nas obras e nas assembleias, o embate de gênero esteve sempre presente para as arquitetas, seja junto aos mutirantes nos finais de semana, seja junto aos peões contratados durante a semana, seja junto aos mestres de obras, seja junto às lideranças dos movimentos. Invariavelmente suas opiniões técnicas e políticas parecem ter sido menos valorizadas e ouvidas que as dos arquitetos e, seus erros, foram apontados com mais rapidez. A vigilância masculina sobre o desempenho profissional feminino se traduziu na necessidade de provar, constantemente, o conhecimento técnico. Resultou, também, na adoção de uma maior firmeza para transmitir ordens, formas de agir e falar que são interpretadas pejorativamente, como de 'brabeza' das mulheres.

Aos conflitos de gênero, acrescentem-se os dos saberes, portanto. Nas obras e perante os colegas do coletivo, sobretudo na época da primeira geração da USINA. A tenra idade das(os) arquitetas(os) contribui para a desvalorização do seu conhecimento por parte dos trabalhadores contratados e dos mestres. Mas o saber de um jovem arquiteto é sempre mais respeitado do que o de uma jovem arquiteta, sobretudo quando seu comportamento forjado no ambiente participativo e mais democrático da USINA e dos mutirões de final de semana, 'atropela' a hierarquia do canteiro convencional instalado durante a semana. Nesses casos, a possibilidade de conflitos de gênero se potencializa, sendo frequente a contestação explícita de sua autoridade técnica - e sua associação a estereótipos pejorativos de gênero - por parte dos pedreiros e serventes 
contratados. Então, se uma jovem de formação universitária em obra é potencialmente portadora de conflitos, isso se potencializa quando a hierarquia é questionada por meio do contato direto entre arquitetas, pedreiros e serventes, sem passar pelo mestre. Perdem-se as referências, as marcações de classe social e de qualificação.

Mas não é esse mesmo o objetivo que se persegue em empreendimentos de trabalho associado que adotam o processo de autogestão? Ocorre que, do ponto de vista das relações de gênero, às dificuldades de quebra de paradigmas no trabalho e na gestão do negócio, introduzidas pelo processo de autogestão, acrescentam-se as dificuldades que as mulheres, de modo geral, têm ao se inserir em culturas profissionais masculinas. Mesmo que, hoje, as mulheres sejam a maioria numérica entre os arquitetos, a referência profissional parece continuar associada a profissionais exitosos - todos do sexo masculino - que com arte e técnica demonstram criatividade, inovação, domínio técnico e conhecimento humanístico amplo. Essa identificação ainda impregna os corações e as mentes dos profissionais de ambos os sexos, que a interiorizam e, por ela, orientam suas ações, sua postura num coletivo profissional, muitas vezes, de forma inconsciente. Além disso, os terrenos do domínio da técnica e da política também continuam associados a valores masculinos, haja vista a pouca permeabilidade à presença feminina em profissões técnicas, tecnológicas e nos espaços públicos da política, particularmente aquele da política partidária. Inevitável, portanto, que se reproduza a divisão sexual do trabalho num em-

\section{Referências}

DAL RI, Neusa Maria. Educação democrática e trabalho associado no contexto político-econômico do movimento dos trabalhadores rurais sem terra. Tese (Livre Docência) - Departamento de Administração e Supervisão escolar da Faculdade de Filosofia e Ciências da Universidade Estadual Paulista, Marília, 2004.

DAL RI, Neusa M.; VIEITEZ, Candido Giraldez. Trabalho associado: cooperativas e empresas de autogestão. Rio de Janeiro: DPeA, 2001.

GAIGER, Luiz Inácio. A dimensão empreendedora da economia solidária: notas para um debate necessário. Outra Economia. Revista Latinoamericana de Economia Social y Solidaria, v. II, p. 58-72, 2. sem. 2008. Disponível em: <http://www. riless.org/otraeconomia>. Acesso em: 08 ago. 2010.

KERGOAT, Danielle. Division sexuelle du travail et rapports sociaux de sexe. In: HIRATA, Helena et al. (Orgs.). Dictionnaire critique du féminisme. Paris: PUF, 2000. p. 3544. (Collection Politique D'aujourd'hui).

LEITE, Marcia de Paula. O trabalho no Brasil nos anos 2000: duas faces de um mesmo processo. In: WORKSHOP A INFORMALIDADE REVISITADA: DAS ORIGENS ÀS NOVAS ABORDAGENS, ABET: Associação Brasileira de preendimento em que todas essas dimensões culturais interagem e se conflitam.

Finalizando, entendemos que a USINA pode ser considerada uma experiência bem sucedida de trabalho associado com forte embasamento político-ideológico entre profissionais qualificados, sob três dimensões, a saber: a longevidade do empreendimento (vinte anos de existência); a manutenção das premissas políticas que orientam suas atividades (trabalhar com habitação popular junto às camadas mais pobres); a adoção e aprofundamento dos princípios de autogestão na administração do negócio. Exposto a variáveis externas que desafiaram e desafiam sua sobrevivência - descontinuidade das políticas de habitação popular mediante subsequentes gestões municipais, estaduais e federais, raras linhas de financiamento, dificuldades de organização popular, entre outras -, o coletivo reafirma sua opção político-profissional ao trabalhar com os movimentos populares em regime de mutirão, em vez de optar por outras modalidades de construção popular. Sabem que não podem 'viver da USINA' e por isso mantêm trabalhos concomitantes que os remunerem com regularidade. O coletivo aceita a precariedade das condições de trabalho, a remuneração abaixo do mercado e irregular, a informalidade dos vínculos de trabalho e entende que essas características são intrínsecas às atividades que escolheram desenvolver como arquitetos(as) militantes. No âmbito interno, apesar dos problemas, têm procurado colocar em prática a autogestão, com ênfase na transparência na gestão financeira e na adoção de um alto grau de democratização interna.

Estudos do Trabalho, Recife, 17 dez. 2009. Mimeografado. LIMA, Jacob. Trabalho flexível e autogestão: um estudo comparativo entre cooperativas de terceirização industrial. In: LIMA, Jacob. (Org.). Ligações perigosas: trabalho flexível e trabalho associado. São Paulo: Annablume, 2007. p. 127-170,

LIMA, Jacob. Trabalho autogestionário e cooperativas: uma introdução ao debate internacional. Campinas, jun. 2008. Mimeografado.

LOMBARDI, Maria Rosa. Perseverança e resistência: a engenharia como profissão feminina. Tese (Doutorado) - Faculdade de Educação da Universidade Estadual de Campinas, São Paulo, 2005.

NOVAES, Henrique. A autogestão como magnífica escola: notas sobre educação no trabalho associado. Revista e-curriculum, São Paulo, v. 5, n. 1, dez. 2009. Disponível em: <http:// www.pucsp.br/ecurriculum>. Acesso em: jan. 2010.

THÉBAUD-MONY, Annie; DRUCK, Graça. Terceirização: a erosão dos direitos dos trabalhadores na França e no Brasil. In: DRUCK,Graça; FRANCO, Tânia (Org.). $A$ perda da razão social do trabalho: terceirização e precarização. São Paulo: Boitempo, 2007. p. 97-118. 


\title{
Associated work, self-management and popular housing: a successful experience
}

\begin{abstract}
This article analyses the research results about an associated work organization among architects, headquartered in the City of São Paulo. Established since 1990, the organization offers technical advisory services to popular housing. At the present, it congregates twelve associated members, eleven architects and one social scientist. It is a collective formed by young people, given that its members are in their twenties and thirties. The scope of this research is to recover the "life history" of the enterprise, identify and analyze possible changes in the work organization in terms of its objectives and activities. It also has attempted to be aware of the sexual division in technical work, of the members appraisal of this alternative experience of work as well as their expectations for the future. Methodologically, the research is classified as a case study and uses documental analysis, personal interviews (eighteen, including members and former members) and participant observation of the group's work meetings as data gathering.
\end{abstract}

Keywords: associated work; autogestionary management; sociology of work; gender relations; architecture.

\section{Trabajo asociado, autogestión y arquitectura popular: una experiencia exitosa}

\begin{abstract}
Resumen
El artículo analiza los principales resultados de investigación sobre una organización de trabajo asociado entre arquitectos/as, ubicada en la ciudad de São Paulo, en la que se dedica a la asesoría técnica para vivienda popular y están activos desde 1990. Actualmente, congregan doce asociados, once arquitectos/as y un científico social. Se trata de un colectivo joven, pues sus miembros tienen entre $25 \mathrm{y}$ 36 años. La investigación objecta recuperar la "historia de vida" del negocio, identificar y analizar posibles cambios en la organización del trabajo, en sus metas y en las actividades. Ha tratado de conocer, asimismo, la división sexual del trabajo técnico y la evaluación de los/las associados/as acerca de esa experiencia como alternativa de trabajo y de las expectativas para el futuro. Metodológicamente, la investigación se define como un estudio de caso y, para la recolección de datos, se ha utilizado el análisis documental, las encuestas personales (dieciocho, con asociados y ex-asociados) y la observación participante durante las reuniones del trabajo colectivo.
\end{abstract}

Palabras clave: trabajo asociado; autogestión; sociología del trabajo; relaciones de género y arquitectura.

Data de recebimento do artigo: 30-01-2011

Data de aprovação do artigo: 10-03-2011 